\title{
Development of a Multimedia Program to Promote Environmental Education of Zoology
}

\author{
Fernando Emilio Valladares Fuente
}

Faculty of Sports, center of studies of Sport Training in High Performance, University Pinar del Río, Pinar del Río, Cuba

*Corresponding author: fernando.valladares@upr.edu.cu

https://riiopenjournals.com/index.php/society sustainability/index

Doi: https://doi.org/10.38157/society_sustainability.v2i3.168

Citation: Fuente, F. E. V. (2020). Development of a Multimedia Program to Promote Environmental Education of Zoology, Society \& Sustainability, 2(3), 1-9. Doi: https://doi.org/10.38157/society_sustainability.v2i3.168

\section{Research Article}

\begin{abstract}
The purpose of this study was to improve the approach of environmental education in a secondary school in Pinar del Río, Cuba. This material was created using a) literature on the theoretical-empirical background of environmental education focused on Zoology and b) a study of student perceptions of the environment using surveys and interviews. Deficiencies noted in the literature and student knowledge guided the design of a multimedia program to teach Zoology to high school students with a focus on an integrated environmental approach. The proposed program includes specialized videos and texts about both global and local fauna. The videos and activities were designed to familiarize students with the fauna and the measures that they should take to protect and help preserve the life of animals and their environments.
\end{abstract}

Keywords: Environmental education, Multimedia, Zoology.

\section{Introduction}

Since early times people have depended directly on their natural environments for food and shelter. Over time, the impact of this dependence has passed from the use of natural resources to meet the essential basics of the overuse of ecosystems. Even a cursory comparison of the abundant and diverse array of animal species of the past with the current list of animals extant today suggests that we should do something urgently to stop, or to at least reduce, the loss of biological diversity at both global and local levels.

Education provides one of the most influential vectors by which this sustainable awareness can be communicated. Many contemporary communication tools are developing rapidly through information technology (IT) and these tools could be useful in transforming the attitudes of young people towards the preservation of animals. For example, Armiñana García (2008) provided a didactic initiative that encourages learning zoology on a deeper level than is usually seen in books. This initiative used computers and exciting learning programs stooped accessible new pathways to knowledge. Some years later, Padilla-Ramirez et al. (2012) enhanced the idea of linking Zoology with IT by proposing a set of online activities to enable students to feel pleasure 
for the new knowledge that they had gained and to foster a spontaneous dedication to the care of animals.

Following these developments in computer-augmented environmental education, Martorelli et al. (2013) created and spread through networks their famous and popular Animali@, which has been able to attract pre-school and primary school-aged boys. Although the usefulness of IT for environmental education was becoming clear by the early part of the last decade, there are still many questions to be answered concerning the theory of environmental education through the study of animals. Cruz \& Toranzo (2014) presented a theoretical background through their community experience. In the next year, Gorriti et al. (2015) established a website to serve as a guide to promote the environmental care of animals using a local Zoo garden in Argentina as its subject. As environmental education has developed on the internet, new resources have flourished. Alonso Ospina \& Murillo Garzón (2016) designed computer-augmented educational materials to improve the study of Chordates in the curriculum and Bargas Chávez (2017) built virtual simulators to promote knowing, understanding and caring in the teaching of Biology.

Many experts on the field have declared that environmental education is in a state of on-going construction, and so its essence, theory, and practice must be found inside the interdisciplinary integration of the topic, the cult of attitude transformation, and critical thinking. Haryono et al. (2017) made a strong attempt to this accomplish the aim, even considering that this explicit objective was not focused on environmental education, but to education in a general scope.

A deeper study of an animal's taxonomy, habitat, and other distinctive features can be done through animal collections, such as the collection described by Hempel \& Beck (2018). Studies of environmental education using animals in Universities have led to new models and statistics, and have linked to other branches such as Pedagogy, Geotourism, and Sciences of the sea (Hernawati et al. 2018; Madang et al. 2019; Pereira et al. 2019; Sellmann et al. 2019).

New information on the threats to sustainable ecosystems and on the efficacy of environmental education as well as on differences in socio-cultural context suggests that there is still much to do in this area of study. Therefore, this research focused on the field of zoology teaching regarding four elements: students' participation, students' access to information, the approach to teaching about the local fauna, and the execution of projects designed to change attitudes. The objective of this research was to present didactic multimedia resources for the environmental education of zoology designed on a theoretical- empirical background to improve students' motivation for this subject. It was hoped that using these resources, students also would increase their autonomy and interactivity in the learning process.

\section{A Review of Related literature}

Most of the research papers examined that were beyond instructive and educational in scope unveiled little integration and compromise for social sectors. This lack of engagement has been unable to support permanent strategies to get people involved in becoming more responsible for the care of animals and their environments. However, one of the roles of environmental education has been to guide people towards the responsible treatment of ecosystems. To achieve this goal relative to Zoology, Rodríguez \& Duellman (1994) produced a guide to promote a scientific basis 
for the preservation of frogs in a local territory of Peru. This early effort filled an important role, but its reach was limited to only one taxonomic group associated specifically with Amazonian wildlife. That said, the guide provided a model for some other tropical areas in the world.

In a study of higher education, Harland (2002) inserted into his lesson activities that made students request information, solve problems, and collaborate while reflecting on every task. It was one of the strongest attempts to create project work for environmental education on the topic of zoology.

Pattengill-Semmens \& Semmens (2003) established a monitoring research project in reef fields, with the help of voluntary partnerships. This research revealed the multiple and diverse world of fish. Over the course of the study, it highlighted the gradual impairment of the coastal waters and the resulting impact on the ecosystem. The results of this study pointed to a route to tackle the effect of man's mismanagement of the reef as a fish habitat. However, the scope of this study was limited as the follow-up strategy needed to be reinforced by additional partnerships or government programs to be extended in other areas.

Keen et al. (2005) tried to encourage the social component of environmental education through suggestions towards sustainable development. The initiative covered the Animal kingdom, but it was very general in scope. In a more targeted study, Hochuli \& Banks (2008) intensified environmental education in Australian Zoology. The taxonomic scope centered on marsupials, birds, and other animals endemic to Australia, although the universal fauna was never ignored. The methodology focused on the student's perception, but it lacked tools to make students aware and engaged in local activities towards animals' environments.

Sneddon et al. (2008) followed a similar geographically focused model but concentrated on the ecosystem around an African lion. He used this attractive scenario to motivate children to get familiarized with animals and helped to generate love for nature at an early age. In addition to environmental education, Snaddon et al. (2008) promoted an environmental Culture in elementary schools in both formal and informal ways.

Short (2009) highlighted zoology in the study of EE and particularly related this study to responsibility. For his approach, he should have revised the concepts of (a) Worried Environmental Consciousness (b) Engaged Environmental Consciousness and (c) Responsible Environmental Consciousness. We make this suggestion because it was the third rank to which he apparently gave more importance. We deduce that there is no true responsibility without support by a process of implication, compromise, and action.

Eryaman et al. (2010) opened a new era in the pedagogy of environmental education for the care and protection of nature. With a sophisticated method, these authors made use of the best of participatory approaches to empower EE through Action Research Study of Nature. The beauty and the clarity of this approach paved the way for other versions of this study to go beyond animals to other branches of the natural sciences.

Other authors, such as Breiting \& Wickenberg (2010), have insisted on the dynamic nature of environmental education, that it can always be enriched by new experiences, no matter the place and the conditions where this teaching process originates. Approaches to treating local animals responsibly are translatable to other animals with common characteristics, although the new 
generation requires an EE that better resembles the epoch around them than the experience we lived in the past.

This social motion view was expanded by Ploeg et al. (2011); using the context of crocodile captivity, they were able to mobilize local citizens to improve the atmosphere of coexistence with the environment. Through their action-research intervention, these authors proved that no matter how dangerous animals can be, ecological balance and environmental harmony is possible with intelligence and tolerance.

To advance EE on the subject of animal care in institutions, Dove \& Byrne (2014) developed a work that facilitated comprehension about and public affection for a local zoo. The activities in their program were designed primarily to attract more clients to the facility, but as time passed, many people embraced the idea of bettering the Zoo conditions.

\section{Material and Methods}

This study was carried out by specialists of Environmental Education (EE) in the University Pinar del Río, Cuba, using their outreach agreement with the general education schools in the province. Some of these specialists had been traditionally engaged in community work and knew empirically how some teenagers mistreated animals in the locality. Some of the students hunted reptiles for fun and, in the rural areas, some were indoctrinated into the vicious culture of dog and rooster fighting. It was the paramount motivation of the authors to study environmental education centered on animals in one of the biggest secondary school of the province: "Carlos Ulloa" High School

The class selected was an 8th-grade class, in the 2017-2018 school year, with a membership of 42 students. This grade was selected specifically because the students (teenagers) take Biology II, which covers the animal kingdom (known in the recent past as Zoology). Some of the research data and the teaching guidance were facilitated by the Biology teacher Norka López Rodríguez (BA). She currently works in this school and joined the team of research as soon as she got aware of the high interests of the University EE Specialists.

To follow a process of cognitive dimension like the one we planned, it was necessary to have a Learning Level (LL) description of the students (Table 1). Level 1 meant that students in this category have an advanced learning coefficient, level 2 are those students with medium learning coefficient, and level 3 are those students who have a low or very low learning coefficient. The majority of the class belonged to the average assimilation rank (Table 1). Therefore, the environmental activities were designed to be very clear with simple language to ensure the success of the didactic proposal.

Table 1: LL Description of the class used in the study

\begin{tabular}{|cccc|}
\hline Number of students & Level 1 & Level 2 & Level 3 \\
\hline 42 & 4 & 30 & 8 \\
\hline
\end{tabular}

The methods used in this research included a survey, an interview, and a pedagogical test. These methods tested the efficacy of environmental education based on the concept used by Emilio \& Fuente (2018), who proposed that environmental education would foster environmental 
behavior. The dimensions evaluated were cognitive, practical, or procedure-based and affectiveevaluative.

\subsection{The survey}

A Survey was applied to evaluate the students' knowledge about general school activities regarding EE.

- Existence of activities in the school leading to environmental education as an interdisciplinary process.

- Presence of a convincing model of environmentalism on the side of teachers, managers, and school workers (concurrence between what they say and the way they behave).

- Presence of literature, instruments, means of promotion in the school and in the local media concerning EE.

- Coordination of school activities with the community for the promotion of environmental issues.

\subsection{The pedagogical test}

The pedagogical test was aimed at evaluating student's knowledge, skills, and values related to the subject of Zoology (during the period and in the outdoor activities). The indicators considered were:

1. Knowledge about the definition of environment and EE

2. Knowledge about the characteristic fauna in diverse regions of the Earth

3. Knowledge about the endangered species in the world

4. Knowledge about the endangered species in Cuba

5. Knowledge about the actions that can be done to protect the local fauna

6. Knowledge about the myths and the truths concerning some animals

\subsection{The interview}

The interview was addressed to the teaching staff of $8^{\text {th }}$ grade at the school understudy. Ten teachers were interviewed; they accepted very collaboratively and contributed with solid and faithful answers. The interview was designed to determine the extent of the teachers' influence upon the students and their influence was categorized as positive, weak, potential, or contradictory.

\section{Results and Discussion}

The survey suggested that:

- There were few activities related to environmental education in the school; the sole strong example was one dedicated to The International day of Environment, June $5^{\text {th }}$.

- $95 \%$ of students declared that their teachers were a convincing model of environmentalism because there was correspondence between what they said and the way they behaved. The students said that the teachers were very good environmental promoters because they asked the students not to mistreat animals and plants and not to pollute the air and the water. 
- $70 \%$ of students declare that there was little literature, equipment, or promotion of EE in the school. They also thought that although the local media (radio and TV) regularly aired some environmental announcements, people did not always follow the good advice promoted about being responsible for environmental problems.

- $87 \%$ of students affirmed that there was a poor connection between the school and the community with respect to environmental activities.

The results of this research suggested that the school system did not significantly influence environmental awareness as claimed. However, it is important to highlight that EE for sustainable development is an important goal, even if this process hasn't matured yet to the level that we would wish it to be. Modeling good practices around the topic, opening dialogues, and helping everyone to compromise to achieve the change is the first thing we all need.

Most of the students had a simplistic definition of EE, mainly related to the naturalistic conception of the environment; some of them confused the native fauna of Africa with the one in India, the fauna of Europe with that of Asia (Table 2). Only a few of them recognized the characteristic fauna of America. Most of them were not familiar with the list of endangered species (animals) in the world or in Cuba. They also lacked knowledge about the actions they could develop to protect their local fauna and sometimes they did not appreciate the value and lifestyles of some animals because of myths about these animals.

Table 2 Percentage of students who answered accurately on the Pedagogical test per the indicators

\begin{tabular}{|cccc|}
\hline Indicators & Percent of students & Indicators & Percent of students \\
\hline 1 & $20 \%$ & 4 & $25 \%$ \\
\hline 2 & $15 \%$ & 5 & $10 \%$ \\
\hline 3 & $10 \%$ & 6 & $15 \%$ \\
\hline
\end{tabular}

Given the weakness of the existing environmental education program and the potential to improve it through online access, a didactic multimedia program was designed and adopted to try to solve these insufficiencies.

\subsection{Design of the didactical multimedia program}

This digital resource was created thorough Mediator.9 to be very accessible and easy to carry from PC to PC, ready to mediate home learning and project work. At the start of the program, a menu allowed students to pick the animal unit that they decided what they wanted to study. The resource did not run in an on-line environment as proposed by Padilla-Ramirez et al. (2012), but it gave the possibility of free information transference with clear and concise questions that could be discussed in face-to-face lessons.

Inside any option of the menu, the user could find videos and text about the chosen animal's classification. This information supported or reinforced the contents taught by the teacher during the lesson on Zoology. The information also included interesting trivia and attractive elements of the animal's habits in its usual habitat. For amphibians, in particular, this multimedia program reinforced the work of Rodríguez \& Duellman (1994) for it provided activities in which students would have to find all the benefits of frogs as biological regulators of the environment in the 
video. It highlighted some of the frogs living in Amazonia, but also one of the smallest frogs in the world, which can be found in Cuba.

To foster knowledge about the national fauna, the multimedia program offered some videos about endemic and endangered species of Cuba and those species that coexist in the National Zoo. Some of the activities provided a friendly way to care about animals and allowed the users to design dialogues to share their views and feelings with relatives and friends in an approach modeled after Dove \& Byrne (2014).

The multimedia program also included a site dedicated to some myths about the fauna in Cuba. This section was narrated by an expert in Zoology of the province of Pinar del Río, and it presented a list of questions to be answered after listening to the expert. The answers to these questions provided data for a companion research project based on the studies of Harland (2002), Keen et al. (2005), and Eryaman et al. (2010), whose contributions centered the study of natural features but also on the social implications of the treatment of animals.

The multimedia program design took into consideration some other outstanding elements:

- In the multimedia program, there was a presence of attractive stories in simple basic language to attract the participation of children as suggested by Snaddon et al. (2008).

- The activities were designed in such a way that the learners must prepare a draft of all the actions they have done to preserve the local fauna around their domestic environment, according to the rank of responsibility scale given by Short (2009).

- The activities were presented at different levels of knowledge and related to the different locations of the learners, as suggested by Breiting \& Wickenberg (2010).

An important aspect of this multimedia program was that it was designed in a Cuban University for use in local schools. This country has been suffering under the weight of the economic embargo imposed by the United States government for more than 60 years. As a result of this embargo, the country has not benefited from technological advancements that enable access to the internet at all educational centers. To ensure that a larger proportion of children could use the program, this multimedia program was designed with no indispensable online structure.

Internet connection is not the only technological problem in Cuba; devices such as flash drives, computers, tablets, and smart telephones for education also have been in short supply. With this multimedia program installed in a school's computer lab, many students would have access to the knowledge at one time. It would require relatively little memory to store on a computer, so it could be easily transported home and adjusted to any PC characteristics. The embargo also has precluded the frequent update of books and workbooks in primary and secondary schools, so this multimedia program can help to fill this critical role in the Cuban educational system as well.

As this multimedia program has been used in Zoology lessons in schools, the material covered in it has been updated and gradually expanded. The feedback on the use of this material in class has allowed the customization of the resource to more closely match the demands, interests, and needs of students and teachers. 


\section{Conclusions}

This paper was developed to improve the environmental education of students studying Zoology and the study concludes with the following:

- The use of IT has increased in environmental education, in both schools and the broader community.

- There are limitations to the knowledge and attitudes of high school students towards animals and the ecosystem linked to these species even with the current EE programs in place.

- The didactic multimedia program, which was based on the theoretical-empirical background of environmental education, facilitated the acquisition of zoological knowledge in students.

- The interactivity of this research project has changed minds and attitudes about global and local fauna to drive the process of EE along the way to its highest stage of this century.

Funding: This Project was funded by the University, Pinar del Río Cuba as part of its territorial environmental programs

Acknowledgement: The author likes to express his gratitude to the Center of Studies of Environment and Natural Resources (CEMARNA) from the University Pinar del Río, for his valuable assistance in data analysis.

Conflict of Interest: The author declares no conflict of interest.

\section{REFERENCES}

Alonso Ospina, C. A., \& Murillo Garzón, O. E. (2016). Material Educativo Computarizado (MEC), para la enseñanza de Zoologia Cordados y su aplicación en el Programa de Licenciatura en Biología y Educación Ambiental de la Universidad del Quindío.

Armiñana García, R. (2008). Sistema de medios de enseñanza asistido por computadoras para el proceso de enseñanza aprendizaje de la zoología General I (Doctoral disertación, Universidad de Ciencias Pedagógicas" Félix Varela". Facultad de Ciencias. Departamento de Biología-Geografía).

Bargas Chávez, V. L. (2017). Los simuladores virtuales como recurso didácticos para la enseñanza-aprendizaje de Zoología ii, en los estudiantes de cuarto semestre de la Carrera de Biología, Química y Laboratorio, período septiembre 2016-marzo 2017 (Bachelor's thesis, Rbba, Unach 2017).

Breiting, S., \& Wickenberg, P. (2010). The progressive development of environmental education in Sweden and Denmark. Environmental Education Research, 16(1), 9-37.

Dove, T., \& Byrne, J. (2014). Do zoo visitors need zoology knowledge to understand conservation messages? An exploration of the public understanding of animal biology and of the conservation of biodiversity in a zoo setting. International Journal of Science Education, Part B, 4(4), 323-342.

Cruz, l. E., \&Toranzo, d. J. L. (2014).Fundamentos teóricos del desarrollo de la dimensión ambiental comunitaria en la enseñanza-aprendizaje de la zoología ii theoretical foundations of the development of the community environmental dimension in the teaching.

Eryaman, M. Y., Yalcin-Ozdilek, S., Okur, E., Cetinkaya, Z., \& Uygun, S. (2010). A Participatory Action Research Study of Nature Education in Nature: Towards Community-based Eco-pedagogy. International Journal of Progressive Education, 6(3).

Emilio F and Fuente V (2018). Some considerations about environmental behavior in the communicative competence for English Language Teaching. Acad. J. Edu. Res. 7(4): 114-118. 
Gorritti, G., Maroñas, M. E., \& Darrigran, G. (2015). Proyecto de elaboración de un portal educativo y empleo de nuevas tecnologías de la informática y la comunicación (NTIC) educativa en el Jardín Zoológico y Botánico de La Plata. In III Jornadas de TIC e Innovación en el Aula (La Plata, 2015).

Harland, T. (2002). Zoology students' experiences of collaborative inquiry in problem-based learning. Teaching in Higher Education, 7(1), 3-15.

Haryono, A., Suatma, M., Savitri, S., \& Araina, E. (2017). Critical Thinking and Activity Capabilities in Collaborative Learning Using Digital Media through Lesson Study in Zoology Subjects. In International Conference on Teacher Training and Education 2017 (ICTTE 2017). Atlantis Press.

Hempel, E., \& Beck, L. A. (2018). MARBURG: Zoological Collection of the Philipps University of Marburg. In: Beck, L. [ed.] Zoological Collections of Germany. Natural History Collections. (pp. 529-540). Springer, Cham

Hernawati, D., Amin, M., Irawati, M., Indriwati, S., \& Aziz, M. (2018). Integration of project activity to enhance the scientific process skill and self-efficacy in zoology of vertebrate teaching and learning. Eurasia Journal of Mathematics, Science and Technology Education, 14(6), 2475-2485.

Hochuli, D., \& Banks, P. (2008). Selection pressures on zoology teaching in Australian universities: student perceptions of zoological education and how to improve it. Australian Zoologist, 34(4), 548-553.

Keen, M., Brown, V. A., \& Dyball, R. (Eds.). (2005). Social learning in environmental management: towards a sustainable future. Routledge.

Madang, K., Tek, O. E., Baharom, S., \& Samsudin, S. (2019, February). The effectiveness of STAD on the learning of fishes in vertebrate zoology among biology education pre-service teachers in Sriwijaya University. In Journal of Physics: Conference Series (Vol. 1166, No. 1, p. 012003). IOP Publishing.

Martorelli, S. L., Martorelli, S. R., \& Sanz, C. V. (2013). Animali@: Material educativo digital para la enseñanza de la Zoología. In XVIII Congreso Argentino de Ciencias de la Computación.

Padilla-Ramirez, J. R., Graniel, D. E. V., Ayala, R. M., \& Sánchez, E. J. (2012). Innovación de ambientes de aprendizaje en la enseñanza de la zoología incorporando educación a distancia y sistemas de respuesta inmediata. Memorias del Encuentro Internacional de Educación a Distancia, (1).

Pattengill-Semmens, C. V., \& Semmens, B. X. (2003). Conservation and management applications of the reef volunteer fish monitoring program. In Coastal monitoring through partnerships (pp. 43-50). Springer, Dordrecht.

Pereira, J., Gomes, P. F., Bondan, J. R., \& Beltrão, L. M. V. (2019). Didactic resources as a geo-education strategy: a means to foster geo-tourism in the Pathways of the South Canyons Geopark project. Applied Tourism, 4(2), 110.

Ploeg, J., Cauilan-Cureg, M., Weerd, M. V., \& de Groot, W. T. (2011). Assessing the effectiveness of environmental education: mobilizing public support for Philippine crocodile conservation. Conservation Letters, 4(4), 313323.

Rodríguez, L. O., \& Duellman, W. E. (1994).Guide to the frogs of the Iquitos region, Amazonian Peru. Natural History Museum, University of Kansas.

Sellmann, D., Beckmann, V., Panzlaff, S., \& Menzel, S. (2019). Zoo educators face common and specific demands and resources: an application of the JD-R model. Environmental Education Research, 25(1), 92-114.

Short, P. C. (2009). Responsible environmental action: Its role and status in environmental education and environmental quality. The Journal of Environmental Education, 41(1), 7-21.

Snaddon, J. L., Turner, E. C., \& Foster, W. A. (2008). Children's perceptions of rainforest biodiversity: which animals have the lion's share of environmental awareness? PLoS One, 3(7).

Tian, R. (2017). Research on Zoology Teaching under the Credit System Mode. Advances in Social Science, Education and Humanities Research, 124, 168-171.

(C) 2020 by the authors. Licensee Research \& Innovation Initiative, Michigan, USA. This article is an open-access article distributed under the terms and conditions of the Creative Commons Attribution (CC-BY) license (http://creativecommons.org/licenses/by/4.0/). 